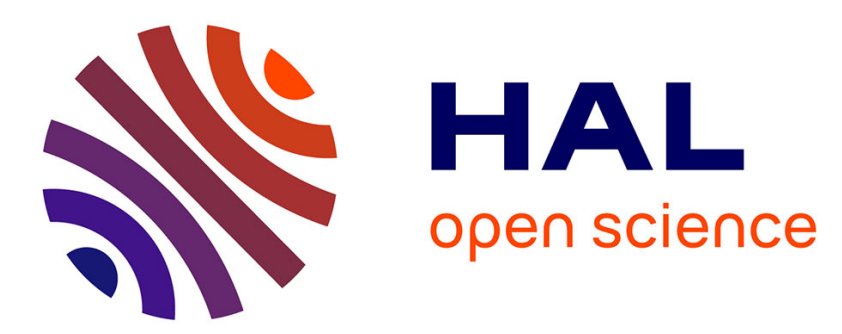

\title{
Development of a control circuit for an electromagnetic smart surface
}

Hanny M Rosalinda, Muneeb U Khan, Laurent Petit, Christine Prelle

\section{To cite this version:}

Hanny M Rosalinda, Muneeb U Khan, Laurent Petit, Christine Prelle. Development of a control circuit for an electromagnetic smart surface. 2015 16th International Conference on Research and Education in Mechatronics (REM), Nov 2015, Bochum, Germany. pp.268-272. hal-02120880

\section{HAL Id: hal-02120880 \\ https://hal.utc.fr/hal-02120880}

Submitted on 6 May 2019

HAL is a multi-disciplinary open access archive for the deposit and dissemination of scientific research documents, whether they are published or not. The documents may come from teaching and research institutions in France or abroad, or from public or private research centers.
L'archive ouverte pluridisciplinaire HAL, est destinée au dépôt et à la diffusion de documents scientifiques de niveau recherche, publiés ou non, émanant des établissements d'enseignement et de recherche français ou étrangers, des laboratoires publics ou privés. 


\title{
Development of a control circuit for an electromagnetic smart surface
}

\author{
Hanny M. Rosalinda, Muneeb U. Khan, Laurent Petit and Christine Prelle \\ Sorbonne universités, Université de technologie de Compiègne \\ CNRS, UMR 7337 Roberval, Centre de recherche Royallieu \\ CS 60319-60203 Compiègne cedex, France \\ hanny.megawati-rosalinda@etu.utc.fr, muneeb-ullah.khan@utc.fr, laurent.petit@utc.fr, christine.prelle@utc.fr
}

\begin{abstract}
Arrayed micro actuators are increasingly used with various kinds of driving methods, especially to realize planar conveyance tasks. Using this concept, the flexible micro electromagnetic conveyor system presented in this paper has been developed. The presented system consists of arrayed elementary cells which can move a mobile pallet placed on its top side. To ensure long range motion flexibility, each cell must be individually controlled to manage the movement of the pallet by selecting the corresponding cells. A control strategy is then needed while avoiding a huge number of wires and power supplies required by each cell. This paper presents a control circuit using a row/column addressing scheme designed to control the presented device. Experimental tests have been done to validate the proposed control circuit design. The results show that the functioning of the device remains the same with the activation of the selected cells only thanks to the developed control circuit.
\end{abstract}

Keywords-Arrayed actuator, smart surface, control circuit, micro conveyor, planar electromagnetic actuator.

\section{INTRODUCTION}

Arrayed micro actuators concept has been investigated for more than 20 years as a breakthrough in the Micro Electro Mechanical Systems (MEMS) field, able to realize complex tasks such as conveyance and fine positioning. It is initially pointed out by Fujita et al., [1] with an example of a ciliary motion system composed of numerous identical actuators. Many works using the same concept performing a conveyance task have been reported as well, including pneumatic micro actuators [2], electro wetting-on-dielectric-actuated aqueous droplets [3], polyimide joint actuators [4] or electromagnetic forces [5], [6].

The micro conveyor system using arrayed actuators often consists of $\mathrm{M} \times \mathrm{N}$ rectangular identical elementary cells in which each of the cell can individually generate actuation force. With the integration of micro manipulators, micro sensors and a control system, this conveyance system is also known as smart surface [7]. The smart surface is able to manipulate several objects, placed upon it, to be delivered to the desired position. It can handle several objects at the same time because the device can give the force that generates motion on objects at many points. The precision of the positioning of the object often depends on the size and on the resolution of each elementary cell.

Each cell in a smart surface must be individually controllable so that complex actions can be obtained by combining elementary actions. Individual control lines could be used to control each cell. However, the number of required control lines, each along with wire and power supply, increases in a proportion to the matrix's size. For large smart surfaces composed of numerous elementary cells, numerous power supplies and control lines are then necessary which can lead to a very high cost. In order to avoid this problem, two main strategies can be found in the literature. The first strategy is to use a decentralized control as proposed in [2], [8], where each cell equipped with micro actuator, micro sensor, and micro control unit, is able to locally decide the control action and share information with their closest neighbor cells. The second approach uses a supervisor control system in order to globally control the cells with an addressing scheme using column and row control lines. Instead of using one control line for one elementary cell, this scheme uses only $2 \times \mathrm{N}$ control lines for the square of $\mathrm{N} \times \mathrm{N}$ elementary cells. So, the number of control lines scales linearly and for large value of $\mathrm{N}$, the required space will be much less than for individual cell control with fewer wires and power supply needed. In literature, numerous studies have been conducted implementing arrayed and addressed based scheme for many applications with various kinds of signals such as water [9], hydraulic [10], electrical signal [11].

In this paper, a control circuit using a row/column addressing scheme designed to control an electromagnetic-based smart surface is presented. The positioning device requires sinusoidal current signals so that a dedicated control circuit is needed. The circuit is able to individually control the arrays and to ensure the large range motion flexibility of the device with limited number of input power supplies. A working principle of the device that specifies the circuit design is described in Section II. A detailed control circuit design is provided in Section III. Experimental tests have been carried out and the results are presented in Section IV.

\section{Actuation Principle of the Device}

The flexible planar conveyor system presented in this paper is based on a micro electromagnetic positioning device previously developed [12]. It consists of four Permanent Magnet Arrays (PMAs) placed at the extremities of a movable pallet (cross shape) and of four fixed driving cells named Planar Electric Drive Coils (PEDC) situated beneath each PMA (see Fig. 1). The pallet displacement is generated using Lorentz force principle when currents are injected into PEDC. With the proposed architecture composed of four PMAs and four PEDCs, the pallet can move along both $x$ - and $y$-axes. Linear Motor ${ }_{1}\left(\mathrm{LM}_{1}\right)$ and $\mathrm{LM}_{2}$ are used for translation along $x$-axis 
and $\mathrm{LM}_{3}$ and $\mathrm{LM}_{4}$ for the translation along $y$-axis.

Each PMA is composed of 14 identical Permanent Magnets with periodically inverted magnetization oriented along $z$-axis [12]. The magnetization and dimensions of the PMs are $1.44 \mathrm{~T}$ and $6 \mathrm{~mm} \times 1 \mathrm{~mm} \times 1 \mathrm{~mm}$, respectively. Each PEDC consists of two coils ( $\mathrm{I}_{1}$ and $\mathrm{I}_{2}$ currents); each coil is injected with sinusoidal currents with $\pi / 2$ relative phase shift. The sinusoidal currents are required to ensure the alignment between the magnetic pole of the PMs and current carrying conductors in order to achieve a smooth displacement of the pallet [12]. With this architecture, not only continuous planar displacement, but also a vertical force can be generated that is useful to reduce friction forces while the mobile pallet moves.

In order to enlarge the pallet stroke, an assembly of several cells forms a smart surface, able to realize planar conveyance tasks, has been designed and manufactured [13]. These cells are then being arrayed and addressed in the form of matrix as seen in Fig. 2. With this design a long stroke can be realized, and is only limited by the size of the smart surface. A prototype of the device composed of $5 \times 5$ elementary cells has been developed in order to validate the proposed principle. Some detailed parameters of the device are presented in TABLE I.

To ensure a high flexibly level, each elementary cell should be able to generate an electromagnetic force along the two displacement axes. For that, two orthogonal sets of PEDCs are being overlapped in one elementary cell. Each cell is then able to move an LM along the two displacements axes which allows the pallet to move over the entire smart surface.

To ensure an independent control of the device along the two axes, many power supplies are needed. Each cell is composed of two pairs of coils for two displacement axes. One hundred power supplies are then required for the control. Moreover, each power supply is controlled using an analog

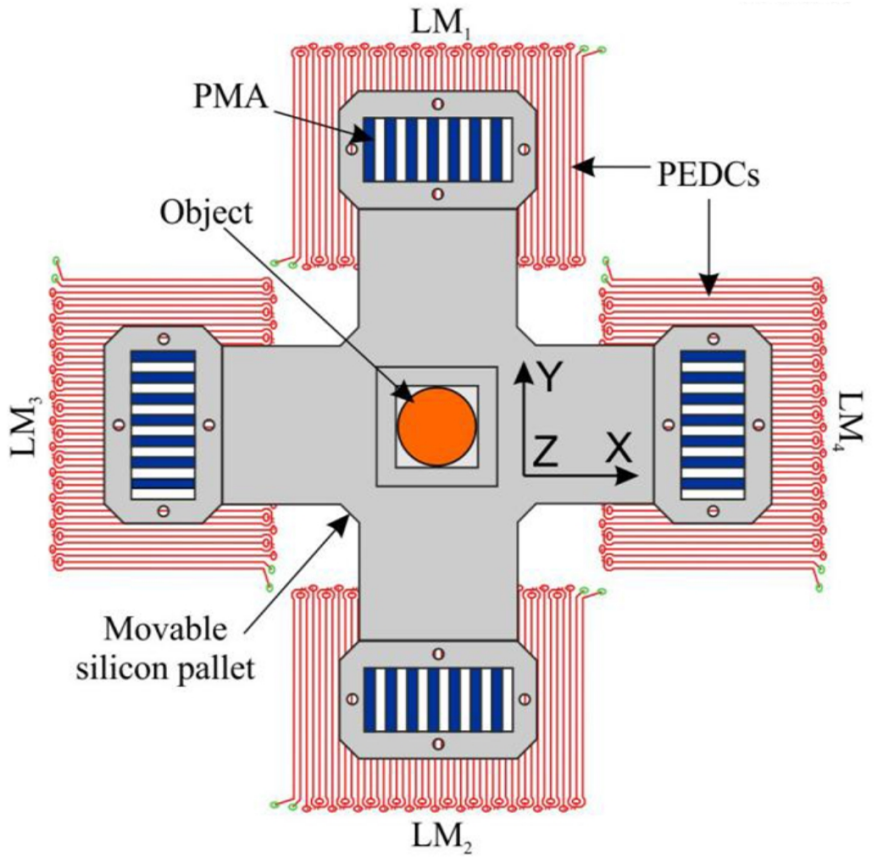

Fig. 1. Planar electromagnetic positioning device layout.

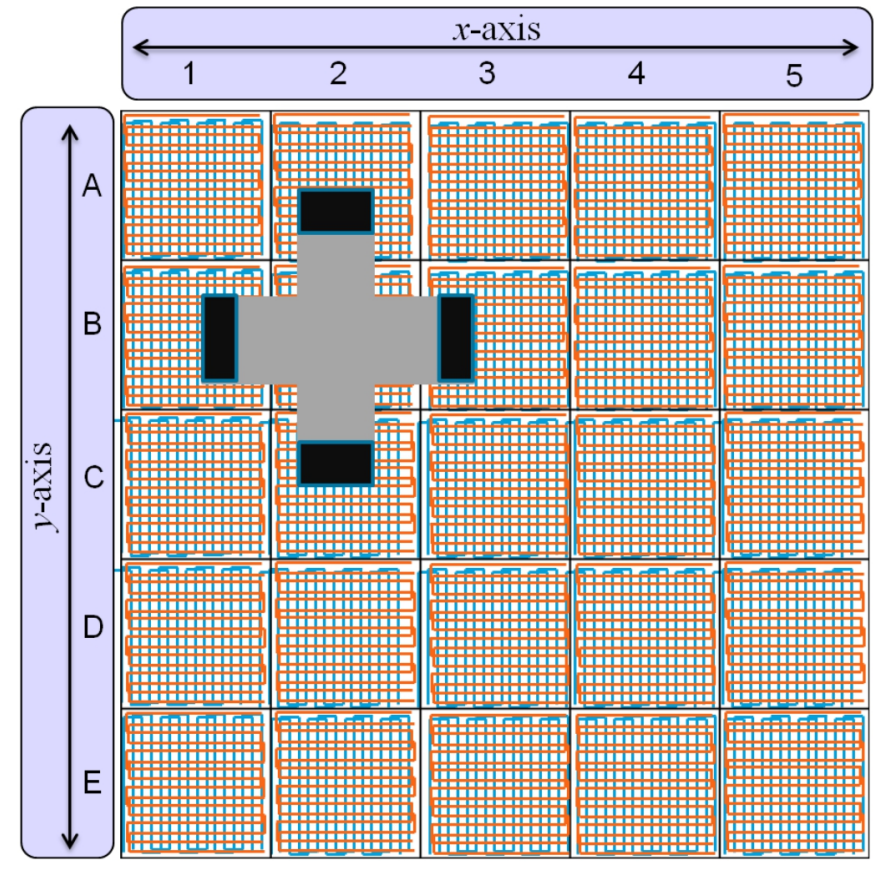

Fig. 2. Smart surface layout composed of $5 \times 5$ elementary cells.

output of a data acquisition board. The cost of the control (i.e., 100 power supplies and 100 analog outputs) would then be very expensive. In order to solve this problem, a hybrid solution (analog/digital) is proposed in this paper.

TABLE I. THE CONVEYOR PLATFORM'S PARAMETERS (IN MM)

\begin{tabular}{lc}
\hline Overall surface dimensions & $130 \times 130$ \\
Elementary cell dimensions & $25 \times 25$ \\
Pitch between wire in PEDC & 0.5 \\
Pallet dimensions & $50 \times 50$ \\
Centre area of pallet & $14 \times 14$ \\
Pallet's thickness & 1 \\
\hline
\end{tabular}

\section{DESIGN OF CONTROL CIRCUIT}

The principle of this circuit is based on the digital selection of the cells which should be supplied with a limited number of power supplies. Therefore, this circuit is capable to select the cells needed to be actuated and to assure that the current will only pass through the selected cells.

Fig. 3, represents the global principle of the circuit that uses $2 \times \mathrm{N}$ switches for a device composed of $\mathrm{N} \times \mathrm{N}$ elementary cells. The row switch $m$ corresponds to all the cells placed in the same row $m$ of the array while the column switch $n$ is connected to all the cells $n$. The selected cells will be supplied by sinusoidal current from the power supply when the corresponding switches for the same row and column of the array are both closed. In this figure, the elementary cells B1 and $\mathrm{B} n$ cells are supplied, by activating control line $\mathrm{B}, 1$, and $n$, while the others are not supplied. The circuit presented in Fig. 3 is able to manage one single current. For each displacement axis, two circuits are then needed (one for each phase).

To control the switches, digital signals are required and are generated using digital outputs from a data acquisition 


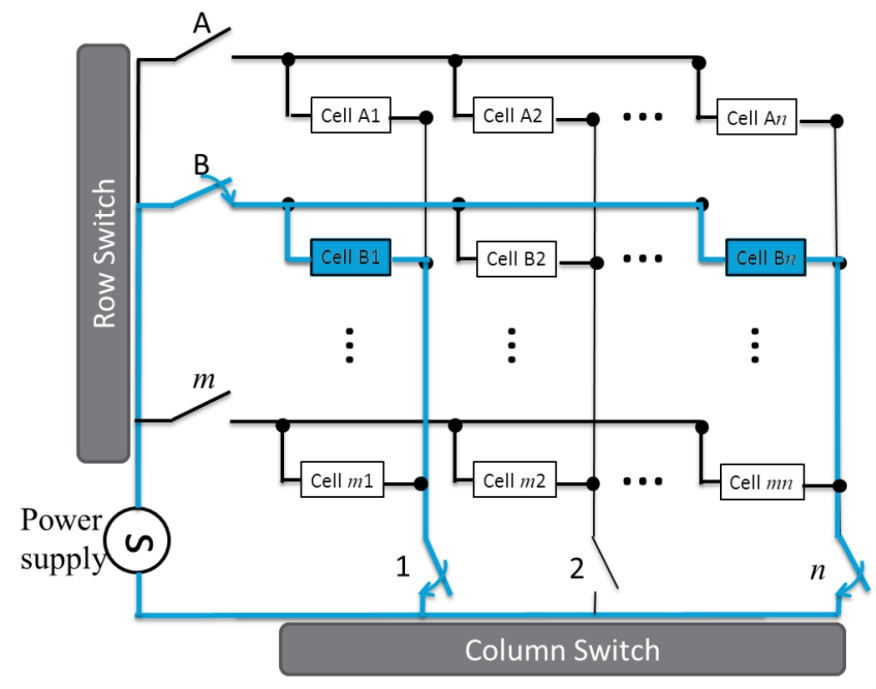

Fig. 3. Schematic layout of the switching circuit for the smart surface.

board. Hence, electrical isolation between the control signals (digital outputs) of the data acquisition board and the power signal (sinusoidal current signals) of the V/I converters has to be assured. Optocouplers with phototransistor output have been selected for the switches. Sinusoidal current with $1.4 \mathrm{~A}$ amplitude is required to activate two cells simultaneously in order to drive two LM of the pallet. For that, power transistors, with low voltage drop have been used to amplify the current that passes through optocouplers from V/I converter to PEDC. Since the components can only pass direct current, the sinusoidal current has to be fully rectified. Bridge of diodes is used as full wave rectifier. Each of the components was chosen considering their peak average forward current, their peak reverse voltage, and their size.

A scheme of the proposed switching circuit is provided in Fig. 4. While control signal "4" is transmitted to an input port of the optocoupler, fully rectified sinusoidal signal flows through output port of optocoupler and a Darlington transistor. The PEDC, considered as an elementary cell, will receive the sinusoidal signal.

An experimental test of the circuit behavior in a simplified scheme has been done to validate the components choice, using three switches (each composed of optocoupler, Darlington transistor, and rectifier bridge) and two selected cells as shown in Fig. 5. The results, presented in TABLE II, show that the two cells receive effectively the same current value $\left(\mathrm{I}_{B 2}\right.$ and $\left.\mathrm{I}_{B 4}\right)$ with different values of the current source. The total voltage drop $\left(\mathrm{V}_{c c}\right)$ is less than the maximum range of the $\mathrm{V} / \mathrm{I}$ converter.

With this scheme, selected cell(s) can be supplied with sinusoidal current by activating the switch via digital control signals. 20 control lines are then required for the two displacement axes, each cell having two coils, in the planar conveyor platform. Physically, only 40 switches and $4 \mathrm{~V} / \mathrm{I}$ converters are needed to control 4 coils $\times 25$ cells.

While the pallet moves along $x$ - and $y$-axis, layer 1 and 2 are used to drive the pallet, respectively. Fig. 6 illustrates an example of the digital signals used to control a simple motion of the pallet. The motion delivers the pallet from starting point to finish point via $1^{\text {st }}$ point; two types of displacements are employed. In first move (displacement along $y$-axis), instead of

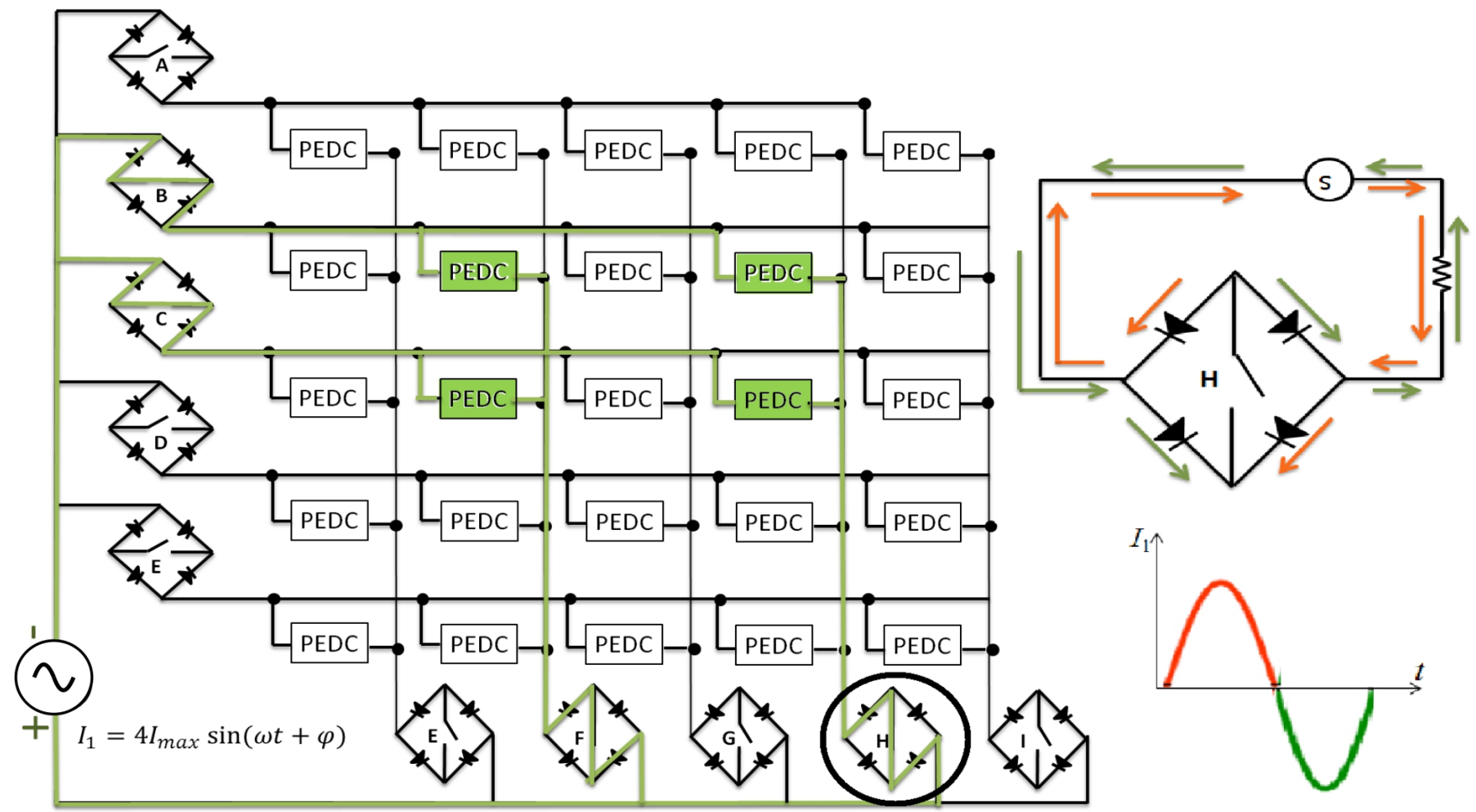

Fig. 4. Schematic layout of the proposed circuit to control the injected sinusoidal current for targeted elementary cell activation. 


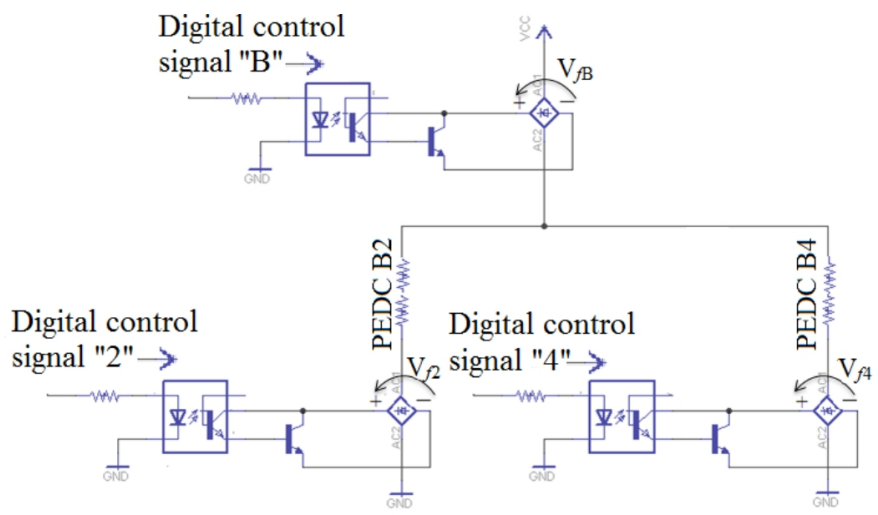

Fig. 5. Test's scheme.
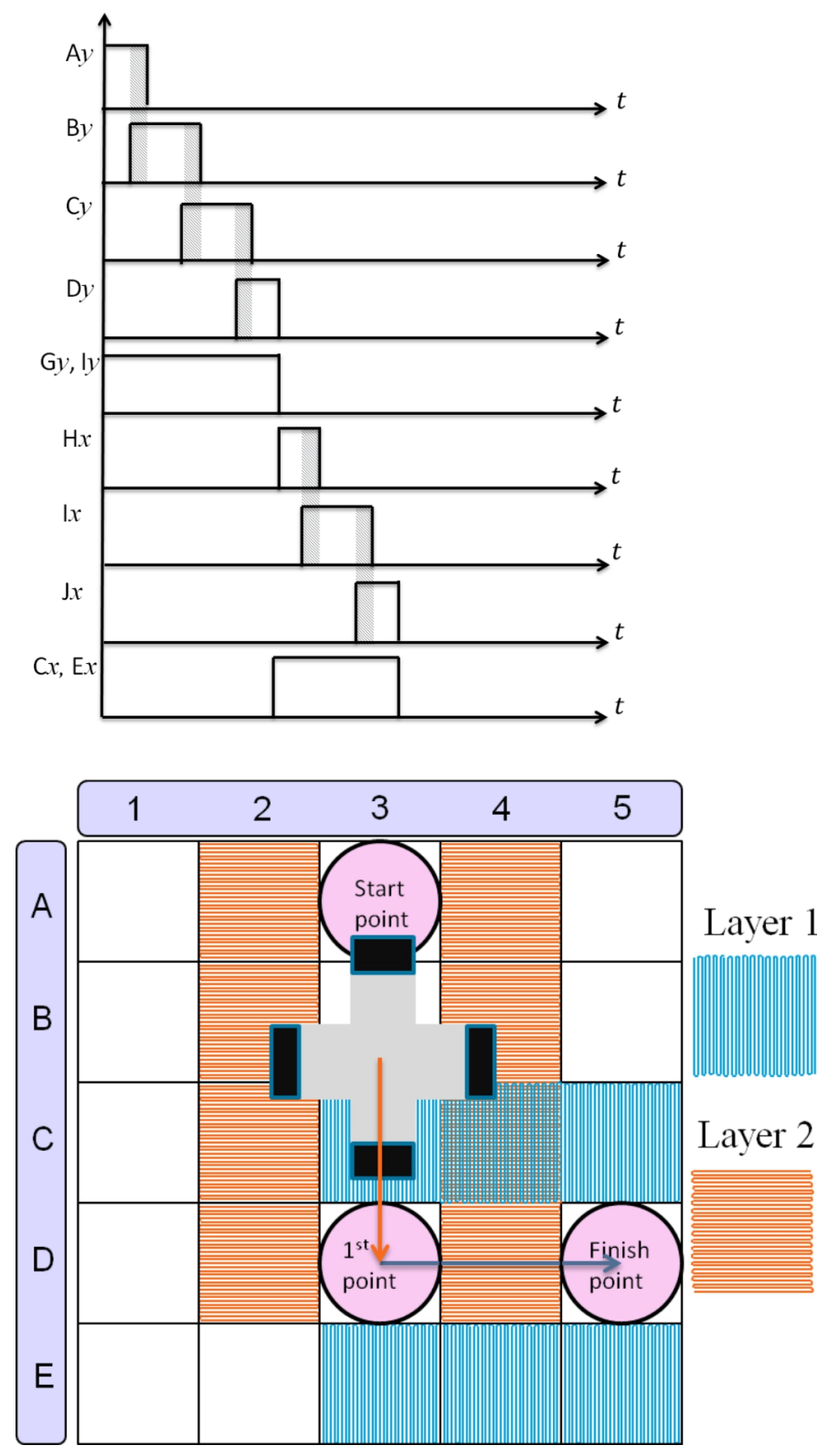

Fig. 6. Digital control signals to realize motions. activating 8 cells along the trajectory, it is sufficient to activate them only when a PMA is passing over them. When the pallet is crossing two cells line, 4 cells are actived simultaneously, as seen in the diagram. Starting from spot "A3", the pallet will be delivered to spot "D3" by sending two sinusoidal signals with the relative phase shift of $\pi / 2$ to two V/I converters and the digital signals to the switches. The same scenario will be applied for the second move along $x$-axis.

TABLE II. TEST'S RESULTS

\begin{tabular}{cccccc}
\hline $\mathbf{I}_{\text {source }}(\mathbf{A})$ & $\mathbf{V}_{c c}(\mathbf{V})$ & $\mathbf{V}_{f 2}(\mathbf{V})$ & $\mathbf{V}_{f 4}(\mathbf{V})$ & $\mathbf{I}_{B 2}(\mathbf{A})$ & $\mathbf{I}_{B 4}(\mathbf{A})$ \\
\hline 0.02 & 3.9 & 1.92 & 1.92 & 0.0088 & 0.0094 \\
0.23 & 5.1 & 2.37 & 2.37 & 0.1125 & 0.1125 \\
0.80 & 6.3 & 2.47 & 2.48 & 0.4025 & 0.4019 \\
1.40 & 7.4 & 2.56 & 2.58 & 0.7063 & 0.6875 \\
\hline
\end{tabular}

\section{EXPERIMENTATION}

The device is supplied by four sinusoidal currents generated from four $\mathrm{V} / \mathrm{I}$ converters (linear conversion, sampling rate of $50 \mathrm{kHz}$, input $[-10 \mathrm{~V},+10 \mathrm{~V}]$ and output $[-10 \mathrm{~A},+10 \mathrm{~A}])$ controlled from analog output of data acquisition board National Instrument ${ }^{\circledR}$ (NI) PCI-6733. The sinusoidal current will pass through the control circuit that allows the current to pass into selected cells only as shown in Fig. 7. The circuit is controlled with digital signals from digital output of PCI-6733. Both sinusoidal currents and digital signals are controlled from computer with the help of LabView ${ }^{\circledR}$ software.

Using a single linear motor (LM) composed of one PMA, experimental tests have been realized in order to validate the operation of the control circuit. A camera has been installed above the platform to capture images of the LM during moving. Firstly, two neighboring cells are activated by selecting their corresponding row and column address on the interface. A $32 \mathrm{~mm}$ displacement along $y$-axis has been made by sending sinusoidal current with $0.8 \mathrm{~A}$ amplitude. The nominal current value is determined based on the results obtained in [13].
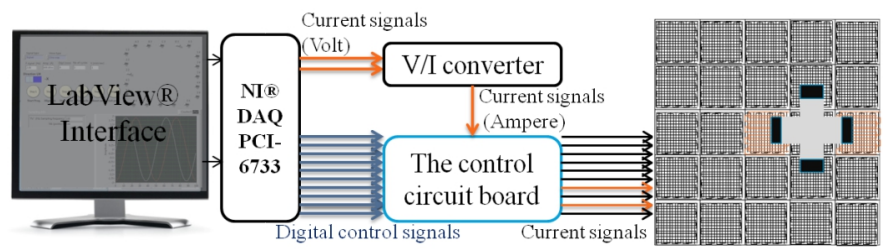

Fig. 7. Schematic layout of the experimental setup.

Several images have been captured during the pallet displacement and few of them are shown in Fig. 8. In this figure, different positions of the LM are shown (initial position at $0 \mathrm{~s}$ and final position at $8 \mathrm{~s}$ ). The LM moved smoothly with the actuation speed of $4 \mathrm{~mm} / \mathrm{s}$ due to the current injected into the cell. At $\mathrm{t}=3.2 \mathrm{~s}$, it also can be observed that the LM could cross from one cell to another. It proves that the functioning of the device is ensured with the activation of selected cells due to the developed control circuit. The cells can be selected and controlled individually with a limited number of power supply. 

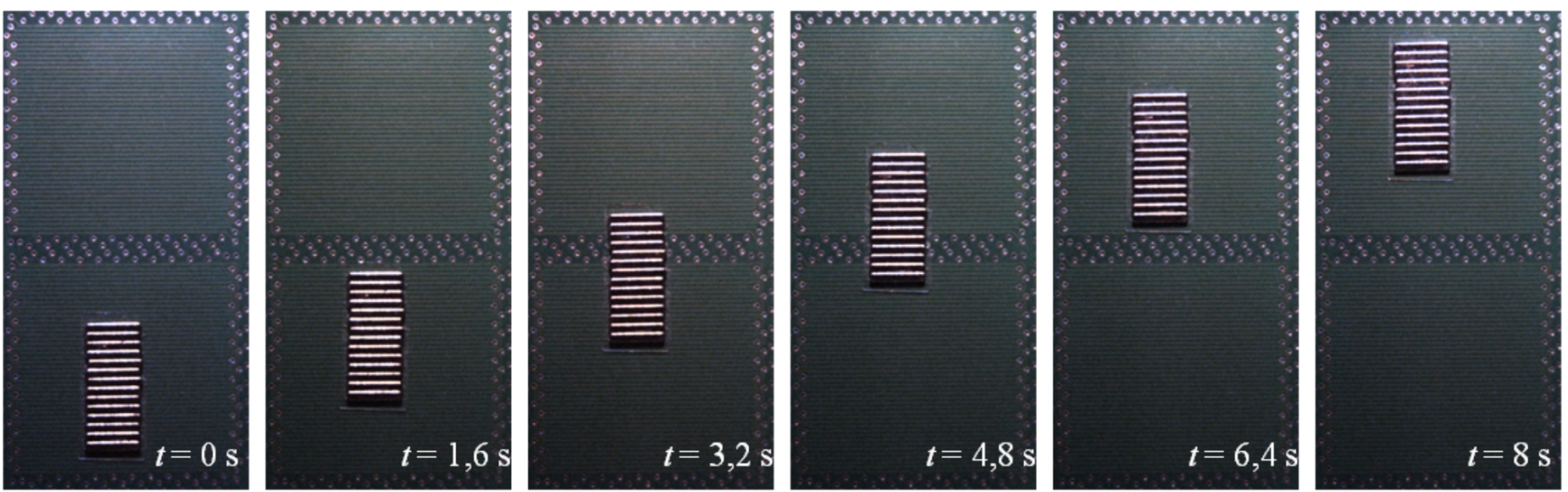

Fig. 8. Captured images of an LM in translation between two elementary cells at different time intervals $t$ in seconds.

\section{CONCLUSION AND FutURE WORK}

In this paper, a control circuit dedicated to a electromagnetic-based smart surface has been developed. The row/column addressing scheme is used so that only 20 control lines, 40 switches and $4 \mathrm{~V} / \mathrm{I}$ converters are needed to control 4 coils $\times 25$ cells of the device. With this scheme, the flexibility of the device can be ensured; selected cell(s) can be supplied with sinusoidal current by activating their corresponding switch. Thus, the movement of the pallet can be managed via computer's interface. An experimental test has been realized to prove the functioning of the circuit design that the cells in the smart surface can be controlled independently and/or simultaneously.

In future, the motion range of the pallet will be increased in order to realize the conveyance task. For that, the algorithm of the activation of digital control signal will be developed. The board of the circuit will also be optimized so that it can be allied together with the smart surface.

\section{ACKNOWLEDGMENT}

This work is a part of the MICROCOSM (MicroCoordinate Measuring Machine) project. It was funded in the framework of the Conseil de la Région Picardie (2014 - 2017) and was also carried out in the framework of the Labex MS2T, which was funded by the French Government through the program Investments for the future managed by the National Agency for Research (Ref: ANR - 11 - IDEX - 0004 - 02).

\section{REFERENCES}

[1] H. Fujita and K. Gabriel, "New opportunities for microactuators," in Solid-State Sensors and Actuators, 1991. Digest of Technical Papers, TRANSDUCERS '91., 1991 International Conference on, June 1991, pp. 14-20.

[2] Y. Fukuta, Y.-A. Chapuis, Y. Mita, and H. Fujita, "Design, fabrication, and control of mems-based actuator arrays for air-flow distributed micromanipulation," Microelectromechanical Systems, Journal of, vol. 15, no. 4, pp. 912-926, Aug 2006.

[3] I. Moon and J. Kim, "Using ewod (electrowetting-ondielectric) actuation in a micro conveyor system," Sensors and Actuators A: Physical, vol. 130-131, pp. 537 - 544 2006, selected Papers from TRANSDUCERS'05, The 13th International Conference on Solid-State Sensors, Actuators and Microsystems - Seoul, Korea, 5-9 June 2005. [Online]. Available: http://www.sciencedirect.com/science/article/pii/S0924424705007582
[4] T. Ebefors, J. Mattsson, E. Kalvesten, and G. Stemme, "A robust micro conveyer realized by arrayed polyimide joint actuators," in Micro Electro Mechanical Systems, 1999. MEMS'99. 12th IEEE International Conference on, Jan 1999, pp. 576-581.

[5] H. Nakazawa, Y. Watanabe, O. Morita, M. Edo, and E. Yonezawa, "The two-dimensional micro conveyer: principles and fabrication process of the actuator," in Solid State Sensors and Actuators, 1997., International Conference on TRANSDUCERS'97, Chicago, USA., vol. 1, Jun 1997, pp. 33-36.

[6] L. Petit, A. Hassine, J. Terrien, F. Lamarque, and C. Prelle, "Development of a control module for a digital electromagnetic actuators array," Industrial Electronics, IEEE Transactions on, vol. 61, no. 9, pp. 47884796, 2014.

[7] D. Barr, D. Walsh, and P. Dudek, "A smart surface simulation environment," in Systems, Man, and Cybernetics (SMC), 2013 IEEE International Conference on, Oct 2013, pp. 4456-4461.

[8] K. Boutoustous, G. Laurent, E. Dedu, L. Matignon, J. Bourgeois, and N. Le Fort-Piat, "Distributed control architecture for smart surfaces," in Intelligent Robots and Systems (IROS), 2010 IEEE/RSJ International Conference on, Oct 2010, pp. 2018-2024.

[9] S. Mascaro, K.-J. Cho, and H. Asada, "Design and control of vast dof wet sma array actuators," in Intelligent Robots and Systems, 2003. (IROS 2003). Proceedings. 2003 IEEE/RSJ International Conference on, vol. 2, Oct 2003, pp. 1992-1997 vol.2.

[10] H. Zhu and W. Book, "Construction and control of massive hydraulic miniature-actuator-sensor array," in Computer Aided Control System Design, 2006 IEEE International Conference on Control Applications, 2006 IEEE International Symposium on Intelligent Control, 2006 IEEE, Oct 2006, pp. 820-825.

[11] S. Braun, J. Oberhammer, and G. Stemme, "Smart individual switch addressing of $5 \times 5$ and $20 \times 20$ mems double-switch arrays," in SolidState Sensors, Actuators and Microsystems Conference, 2007. TRANSDUCERS 2007. International, June 2007, pp. 153-156.

[12] M. Khan, N. Bencheikh, C. Prelle, F. Lamarque, T. Beutel, and S. Büttgenbach, "A long stroke electromagnetic $X Y$ positioning stage for micro applications," Mechatronics, IEEE/ASME Transactions on, vol. 17, no. 5, pp. 866-875, 2012.

[13] N. Arora, T. Dang, L. Petit, M. Bosch-Mauchand, J. Daaboul, and C. Prelle, "Contribution to microfactory technologies: A flexible conveyor and its dedicated control system," in in IWMF2014, 9th INTERNATIONAL WORKSHOP ON MICROFACTORIES, Honolulu, USA,, 2014. 